\title{
Assessment of total body fat in infancy from skinfold thickness measurements
}

\author{
M. J. DAUNCEY, GILLIAN GANDY, AND DOUGLAS GAIRDNER \\ From the MRC Dunn Nutrition Unit, Cambridge, and Cambridge Maternity Hospital
}

SUMMARY A formula is given, allowing a value for total body fat to be calculated from skinfold thickness measurements at two sites (subscapular and triceps), in conjunction with nine body dimensions. For newborn infants total body fat so calculated accorded satisfactorily with published data from cadaver analyses. The formula has been tentatively applied to infants up to the age of 40 weeks, and to preterm infants. The difference between the growth of male and female infants was analysed in a series of 27 normal infants; the greater growth of musculoskeletal tissue in the male contrasted with the relatively greater growth of fat tissue in the female.

As much as one-quarter of an infant's body is composed of fat, yet at present we have no means by which this fat can be measured even approximately, and the only data that we have for infants come from cadaver analyses of perinatal deaths. Skinfold thickness measurements are now a well established means of assessing the thickness of subcutaneous fat at all ages, including infancy; it therefore seemed worthwhile to see whether they could be used to provide some estimate of total body fat.

A number of formulae have been proposed whereby skinfold measurements can be used to predict total body fat (TBF). They have depended for validation on estimating TBF by hydrostatic weighing, measurement of total body water by deuterium oxide, or of total body potassium with ${ }^{40} \mathrm{~K}$. Though several of these methods have been applied to children (Hammond, 1955; Durnin and Rahaman, 1967; Brook, 1971) none are applicable to infants. Therefore, in the absence of any direct method for validating a formula predicting TBF in infants, we have had recourse to indirect means.

\section{Material and methods}

Twenty-seven normal term infants were studied: 15 boys and 12 girls. Measurements of skinfold thicknesses and of various body dimensions were made from birth at intervals of 2-3 weeks for the first 4 months, and thereafter at approximately 6weekly intervals up to 40 weeks. Measurements were also made on 25 preterm infants with birthweights below $2500 \mathrm{~g}$ who were studied from birth up to Received 2 August 1976
3-4 months, but only a few of these results are reported in this paper.

The following measurements were made using the techniques given in Weiner and Lourie's (1969) Handbook: circumferences, with a tape measure (plastic, $2 \mathrm{~cm}$ wide, checked against a steel rule), of head (fronto-occipital), chest (at level of nipples), mid-upper arm, mid-thigh and calf; lengths, with a light plastic caliper, of upper arm (inferior border of acromion to tip of olecranon) and lower arm (tip of olecranon to tip of the lateral styloid). A measuring board was used for supine length and crown-rump length. Skinfolds (subscapular and triceps) were measured with the Harpenden caliper, using the technique described by Tanner and Whitehouse (1975) (see Discussion). Limb measurements were made on the left side.

A model of the body can be made up of a sphere, the head; a cylinder, the trunk; and two pairs of cylinders, the upper and lower limbs (Fig. 1). The head is assumed to be effectively devoid of subcutaneous fat; its diameter $(d)$ is the circumference $\div \pi$. The trunk is taken to be a cylinder of length equal to the crown-rump length minus the diameter of the head sphere $(C R-d$, Fig. 1) and circumference equal to the chest circumference. The upper limbs are taken to be cylinders of length equal to the sum of the lengths of upper and lower arms ( $a$, Fig. 1), the circumference being that of the upper arm. The lower limbs are taken to be cylinders of length equal to the supine length minus the crownrump length $(1-C R$, Fig. 1), and of circumference equal to the mean of the circumferences measured at mid-thigh and calf. 


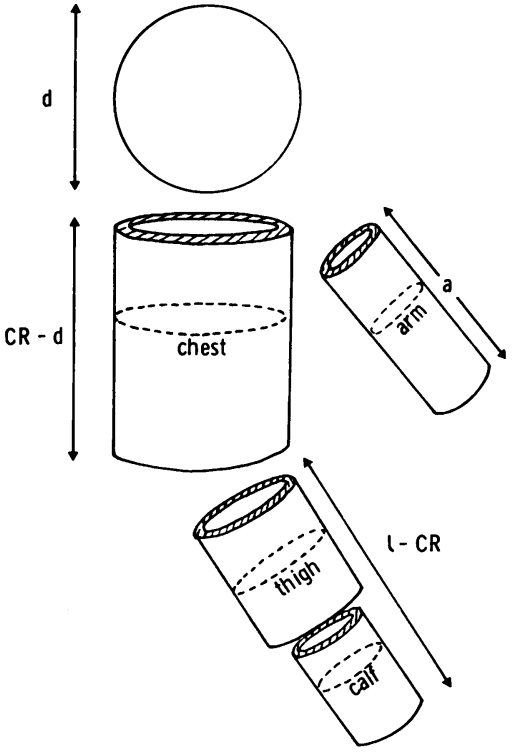

Fig. 1 Model of body with subcutaneous fat layer (hatched). $d=$ diameter of head; $C R=$ crown-rump length; $l=$ supine length; $a=$ arm length.

Since the volume of a thin cylindrical shell of thickness $\theta$, covering a cylinder of length $l$, and circumference $c$ is $\theta c l$, the volume of the layer of fat covering the different sections of the body can be expressed as follows (linear measurements in $\mathrm{cm}$ ):

(A) Volume of fat covering trunk $(\mathrm{ml})=$ (crownrump length-diameter of head) $\times$ (circumference of trunk) $\times \theta_{\text {trunk }}$.

(B) Volume of fat covering upper limb $(\mathrm{ml})=$ (length of upper arm + length of lower arm) $\times$ (circumference of upper arm) $\times \theta_{\text {arm }}$.

(C) Volume of fat covering lower limb $(\mathrm{ml})=$ (supine length -crown-rump length) $\times \frac{1}{2}$ (circumference of mid-thigh +circumference of calf) $\times$ $\theta_{\text {leg. }}$

Summing these, the weight (g) of total body fat is given by $0.9(\mathrm{~A}+2 \mathrm{~B}+2 \mathrm{C})$; the factor 0.9 being the density of human fat (Keys and Brozek, 1953). TBF can be expressed either as a percentage of body weight, or in absolute terms as weight (kg). By subtracting the latter from the body weight a value for the fat-free body weight is derived.

\section{Results}

Thickness of subcutaneous fat layer related to skinfold thickness. The caliper measurement of a skinfold includes a double layer of dermis. To estimate this component, some observations were made on 14 infants aged from 1 day to 6 months who were undergoing surgery (for hernia, pyloric stenosis, or oesophageal atresia). The thickness of the dermis layer was measured directly at the skin incision with a steel rule, and a mean value of $1 \mathrm{~mm}$ was obtained. (A value of the same order was obtained for adults by Barker, 1951).

The relation of skinfold thickness by caliper to subcutaneous tissue thickness as measured by $x$-ray was studied by Hammond (1955) in children aged 1-15 years. In Fig. 2, curve B is plotted from Hammond's data, where the thickness of subcutaneous tissue includes the dermis layer. If $1 \mathrm{~mm}$

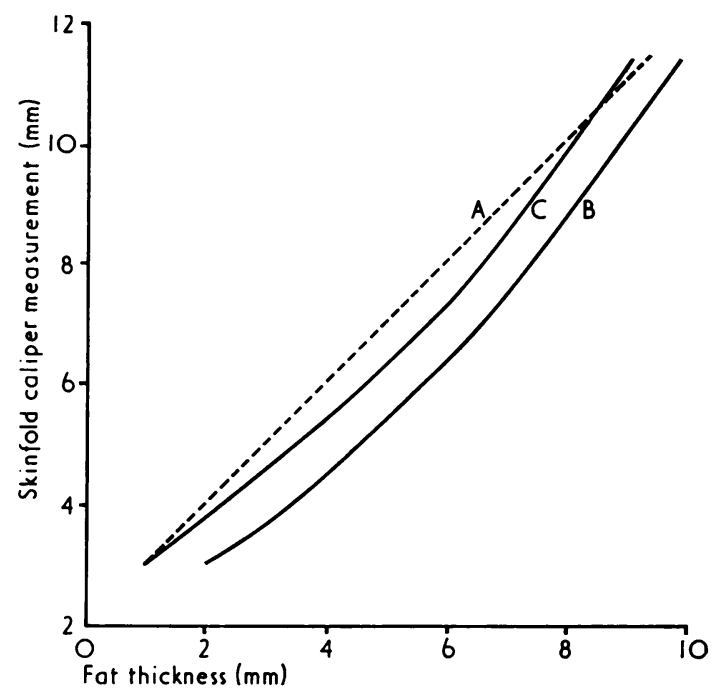

Fig. 2 Thickness of subcutaneous fat layer $(\theta)$ related to skinfold caliper measurement $(S)$. Line $A$, equation $\theta=S-2$; curve $B$, from data of Hammond (1955); curve $C$, as curve $B$, but allowing for $1 \mathrm{~mm}$ thickness of dermis layer (see text).

is allowed for the dermis layer, curve $\mathbf{C}$ is obtained, which then relates the thickness of strictly subcutaneous fat tissue to the observed skinfold thickness. We have empirically taken the fat thickness $(\theta)$ as 2 $\mathrm{mm}$ less than the skinfold thickness (S), i.e. $\theta=$ $S-2$, and this relation is represented by line $A$ in Fig. 2. The fact that line A lies fairly close to curve $\mathrm{C}$ therefore provides some justification for the empirical relation we have used to derive fat thickness from skinfold measurement.

We have made the further assumption that the triceps skinfold is representative of the fat layer covering both upper and lower limbs. Thus we have employed the following formulae (measurements in $\mathrm{cm}): \theta_{\text {trunk }}=$ subscapular skinfold $-0 \cdot 2, \quad \theta_{\text {arm }}=$ $\theta_{\text {leg }}=$ triceps skinfold $-0 \cdot 2$. 
Application to newborn infants. The many large assumptions and approximations involved in our use of skinfolds for predicting TBF make it essential to test the method, if possible. For the newborn this can be done because several authors have made complete chemical analyses of cadavers from perinatal deaths. Data for 103 such subjects in publications from 1863 onwards were recently collected by Brans et al. (1974). They concluded that TBF $\%$ was linearly related to body weight. Fig. 3 shows the regression line $( \pm 2 \mathrm{SD})$ taken from their paper, together with our own data from TBF as derived from skinfold measurements for newborn infants ( $<12$ days old) with weights ranging from $1 \cdot 1$ to $4.4 \mathrm{~kg}$. Our results accord reasonably well with

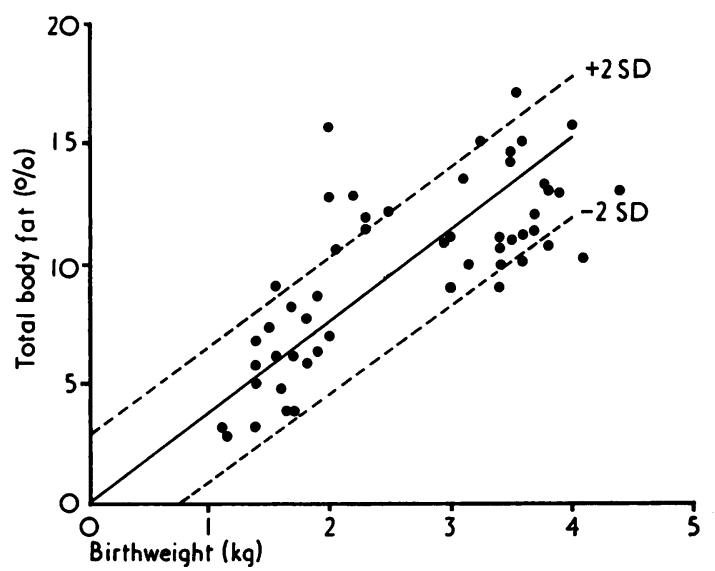

Fig. 3 Percentage body fat related to body weight in newborn infants. The graph showing mean $\pm 2 S D$ is reproduced from Brans et al. (1974) based on cadaver analyses. Results shown for 52 newborn infants of present series, total body fat derived from skinfold measurements.

those obtained by direct analyses, with 41 of our 52 observations falling within the \pm 2 SD range. At the lower range of birthweights $(<2 \mathrm{~kg})$ the data marshalled by Brans et al. (1974) are adequate to allow the conclusion that TBF \% increases with birthweight in a linear fashion. For subjects falling within the normal range of birthweight $(>2.5 \mathrm{~kg})$ conclusions are less certain, since their series included only 14 cases in this range. In our own series there were 27 cases with birthweight $2 \cdot 5-4 \cdot 4 \mathrm{~kg}$ : inspection of Fig. 3 shows that for these subjects $\mathrm{TBF} \%$ was unrelated to birthweight, with a mean value of approximately $10 \%$ throughout the range, but the paucity of cadaver analyses for comparison prevents appraisal of the validity of this result.
Application to older infants. No data exist for TBF in infants other than newborns. If, however, the method is assumed to be valid for older infants, Fig. 4 shows the calculated results for TBF \% from birth to 40 weeks, for the boys (15) and girls (12) of our series. Mean values for TBF at birth were $11 \%( \pm 2 \cdot 0 \mathrm{SD})$ for boys, and $13 \%( \pm 1 \cdot 7)$ for girls. After birth mean TBF increased rapidly to approximately $22 \%$ at 20 weeks, and remained at about this value until the end of the period of observation at 40 weeks. At all ages mean TBF \% for girls exceeded that for boys, though the difference $(1 \cdot 62 \pm 1 \cdot 16)$ was not significant.

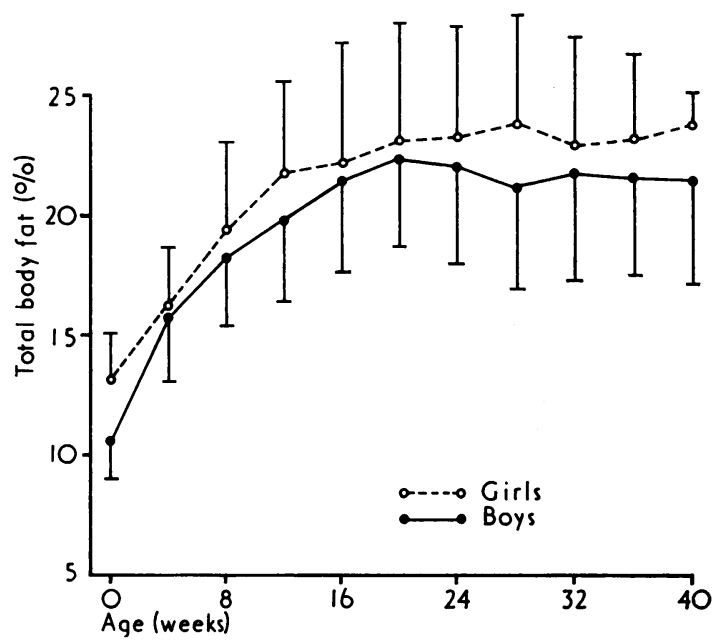

Fig. 4 Mean total body fat as percentage of body weight in 15 male and 12 female infants from birth to 40 weeks. The vertical lines represent $1 S D$.

Fig. 5 shows mean body weight, fat-free weight, and TBF (kg) for both boys and girls from birth to 40 weeks. (Supine lengths for the series are not given; they conformed closely to normal standards, with the boys on average $1.59( \pm 0.69$ SD) $\mathrm{cm}$ longer than the girls during this period). As expected, the mean body weight of boys was consistently more than that of girls ( $P<0.05$ for 4,8 , and 12 weeks). The weight of fat was at first virtually the same for boys and girls, rising from a mean of about $0.4 \mathrm{~kg}$ at birth to $1.8 \mathrm{~kg}$ at 24 weeks; thereafter it remained at about $2 \mathrm{~kg}$, the mean values for girls being consistently slightly higher than those for boys. The fat-free weight was consistently higher for boys than girls throughout the period from birth to 40 weeks, the average sex difference over the period being $0 \cdot 40( \pm 0 \cdot 18 \mathrm{SD}) \mathrm{kg}$. 


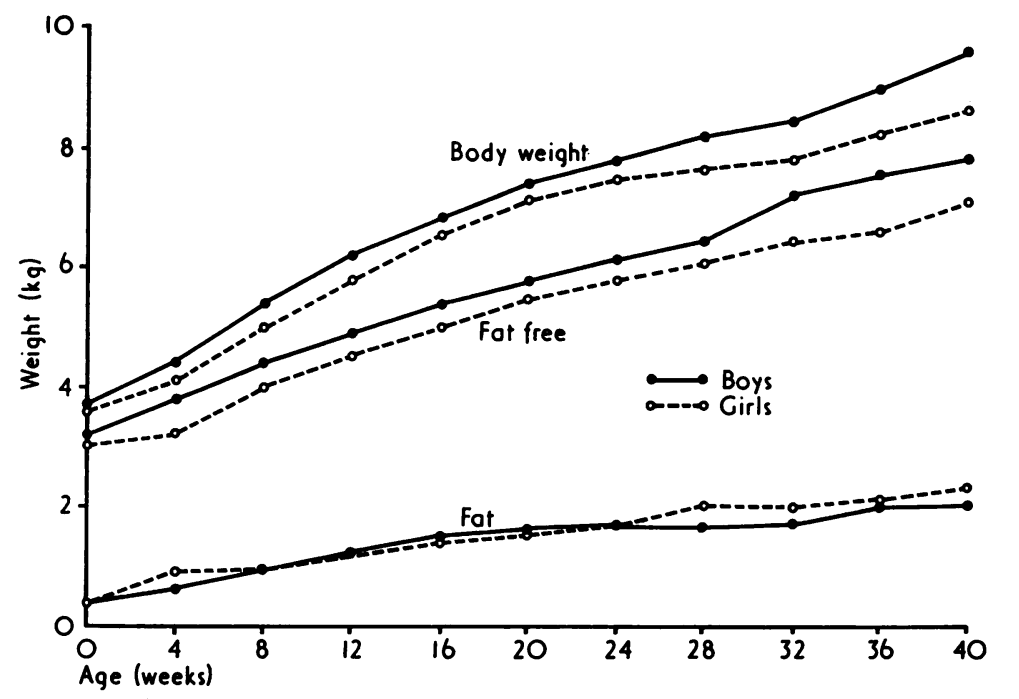

Fig. 5 Mean body weight, fat-free weight, and weight of body fat in 15 male and 12 female infants from birth to 40 weeks.

Application to preterm infants. Fig. 6 shows the course of fat growth in 2 infants, born at 32 and 34 weeks' gestation. Initially the characteristic poverty of subcutaneous fat covering the preterm infant is shown by the very low values of TBF, $6 \%$ and $5 \%$ respectively. Both infants thrived and put on fat rapidly so that by 40 weeks' gestational age TBF

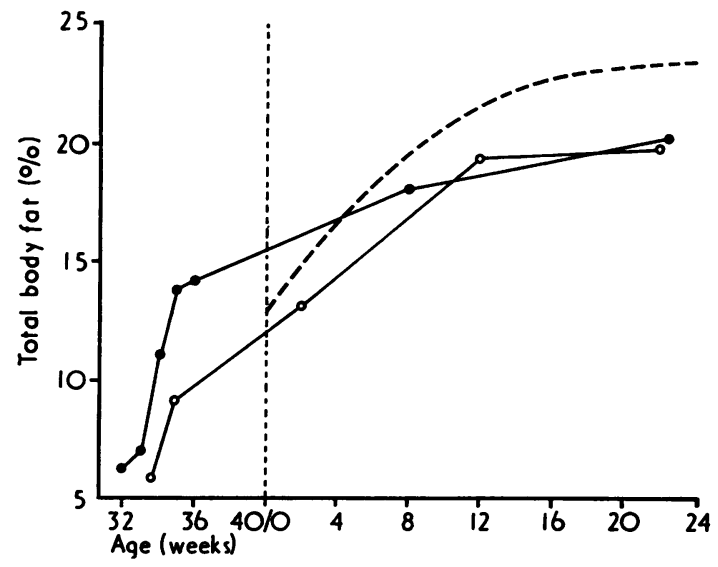

Fig. 6 Total body fat from birth to 7 months in 2 preterm (female) infants born at 32 and 34 weeks' gestation. Mean TBF for normal female infants shown by broken line.

$\%$ had reached a value appropriate for a normal newborn baby. Thereafter fat growth continued as in a normal infant, and TBF rose to approximately $20 \%$.

\section{Discussion}

Any formula which predicts total body fat from skinfold thickness measurements involves an assumption that the amount of subcutaneous fat relates closely to total body fat. Observations made at surgical operations or post mortem suggest that in infants the amount of deep body fat in the abdominal and perirenal sites is small relative to the subcutaneous fat. D. A. T. Southgate and E. Hey (personal communication, 1975) dissected out the depot fat in cadavers from perinatal deaths and found that in 7 fetuses weighing more than $2.5 \mathrm{~kg}$, who were close to term, the deep fat accounted for $21.0 \pm 6.96 \%$ (mean \pm SD) of the total body fat, with a range of 13.9 to $32.5 \%$. In 3 infants over 3 $\mathrm{kg}$ who died virtually at term the mean was $17 \cdot 0 \%$. In the newborn infant it is therefore likely that $70-80 \%$ of TBF is subcutaneous. The proportion of TBF sited in the subcutaneous layer is reported to remain about the same in an individual with changes in adiposity (Durnin and Womersley, 1974), however there are no observations on this point in infants.

While the formula used in the present study was initially derived from a theoretical model, we would not place emphasis on this aspect, but rather regard it as largely empirical. Indeed, since the two skinfold measurements are the main determinants of the calculated value for TBF, a simpler formula involving fewer body measurements might well have proved equally satisfactory.

Validation of the formula has had to depend upon the following. (1) In the newborn the values 
for TBF derived from skinfold measurements have been compared with TBF measured directly in cadavers. (2) At later ages, our values for TBF have proved consistent enough to enable the characteristically different growth pattern of boys and girls to be analysed with seemingly meaningful results.

The reliability of the method depends almost wholly on that of the skinfold measurements. These were made with the Tanner and Whitehouse (1975) technique, with the caliper applied for no more than a few seconds. The caliper was usually applied several times until a consistent reading was obtained. With practice we were able to get reliable results with the infants during the first month of life. Between 1 and 6 months the baby is less prepared to keep still so that accurate measurements become harder. Brans et al. (1974) observed that with newborn infants, compression of skinfolds by the caliper if left in position caused the skinfold thickness to decline exponentially over 60 seconds. Some subsequent authors working with newborn infants have preferred to take caliper readings after a definite time or after waiting for the value to become constant (Whitelaw, 1976), a method which leads to substantially lower values. The technique we have used has the advantage of being applicable to infants of all ages, and our skinfold values are very similar to those published by earlier workers using the same technique for newborn (Gampel, 1965) and older infants (Hutchinson-Smith, 1973).

Between birth and 40 weeks, the girls in our series had a higher mean percentage of TBF than the boys. At birth mean skinfold measurements were slightly larger for girls than for boys (mean $\pm \mathrm{SD}$; $\mathrm{mm}$ : subscapular, boys $5 \cdot 1 \pm 1 \cdot 10$, girls $5 \cdot 3 \pm 0 \cdot 70$, triceps, boys $4 \cdot 9 \pm 1 \cdot 67$, girls $5 \cdot 0 \pm 0 \cdot 73$ ), the converse applying to body weight and supine length. Larger skinfolds in girls at birth were also recorded by Gampel (1965) and Farr (1966) and recently by Oakley et al. (1977) in a series large enough for the difference to be statistically significant.

In later infancy, Hutchinson-Smith (1973) followed 200 infants from 1 month after birth to 1 year, and found no difference between the skinfolds of boys and girls. After 1 year there is general agreement that girls tend to have larger skinfolds than boys (Tanner and Whitehouse, 1975). Even if the skinfold thicknesses of boys and girls were the same, this still implies that girls with their lower average weight must have a larger proportion of subcutaneous fat, as our values for percentage TBF in Fig. 4 show. That the growing male infant, with his more rapid gain in fat-free weight, lays down relatively more musculoskeletal and less fat tissue than does the female is indicated by the results shown in Fig. 5.

In conclusion, we suggest that it is useful to the clinician to be able to translate skinfold measurements into terms of 'total body fat', since whether or not the values so obtained are correct in absolute terms, their use enables the proportion of body fat in different infants to be compared.

We thank Dr. W. A. Marshall for making available computer facilities at the Institute of Child Health, London, and for advice thereon; and Mr. D. E. Walters, ARC Statistical Unit, Cambridge, for statistical advice.

\section{References}

Barker, D. E. (1951). Skin thickness in the human. Plastic and Reconstructive Surgery, 7, 115-116.

Brans, Y. W., Sumners, J. E., Dweck, H. S., and Cassidy, G. (1974). A noninvasive approach to body composition in the neonate: skinfold measurements. Pediatric Research, 8, 215-222.

Brook, C. G. D. (1971). Determination of body composition of children from skinfold measurements. Archives of Disease in Childhood, 46, 182-184.

Durnin, J. V. A., and Rahaman, M. M. (1967). The assessment of the amount of fat in the human body from measurements of skinfold thickness. British Journal of Nutrition, 21, 681-689.

Durnin, J. V. A., and Womersley, J. (1974). Body fat assessed from total body density and its estimation from skinfold thickness: measurements of 481 men and women aged from 16 to 72 years. British Journal of Nutrition, 32, 77-97.

Farr, V. (1966). Skinfold thickness as an indication of maturity of the newborn. Archives of Disease in Childhood, 41, 301-308.

Gampel, B. (1965). The relation of skinfold thickness in the neonate to sex, length of gestation, size at birth and maternal skinfold. Human Biology, 37, 29-37.

Hammond, W. H. (1955). Measurement and interpretation of subcutaneous fat, with norms for children and young adult males. British Journal of Preventive and Social Medicine, 9, 201-211.

Hutchinson-Smith, B. (1973). Skinfold thickness in infancy in relation to birthweight. Developmental Medicine and Child Neurology, 15, 628-634.

Keys, A., and Brozek. J. (1953). Body fat in adult man. Physiological Reviews. 33, 245-325.

Oakley, J. R., Parsons, R. J., and Whitelaw, A. G. L. (1977). Standards for skinfold thickness in British newborn infants. Archives of Disease in Childhood, 52 (in press).

Tanner, J. M., and Whitehouse, R. H. (1975). Revised standards for triceps and subscapular skinfolds for British children. Archives of Disease in Childhood, 50, 142-145.

Weiner, J. S., and Lourie, J. A. (1969). Human Biology. A Guide to Field Methods. IBP Handbook No. 9. Blackwell, Oxford.

Whitelaw, A. G. L. (1976). Influence of maternal obesity on subcutaneous fat in the newborn. British Medical Journal, 1, 985-986.

Correspondence to Dr. M. J. Dauncey, MRC Dunn Calorimetry Group, Institute of Animal Physiology, Babraham, Cambridge. 